\title{
A EDUCAÇÃO AMBIENTAL NA LICENCIATURA EM COMPUTAÇÃO DO CAMPUS PORTO NACIONAL DO INSTITUTO FEDERAL DO TOCANTINS - IFTO
}

\author{
Paulo César de Sousa Patrício ${ }^{1}$ \\ Lilissanne Marcelly de Sousa ${ }^{2}$ \\ Márcia Dall'Agnol ${ }^{3}$ \\ Cynthia Souza Oliveira ${ }^{4}$ \\ Sergio Tulio Pereira Machado ${ }^{5}$ \\ Cleyovane Lemos Ribeiro ${ }^{6}$
}

Resumo: $O$ presente artigo trata-se de uma pesquisa sobre a Educação Ambiental e os desafios vivenciados pelos professores bacharéis em computação no curso de Licenciatura em Computação do Campus Porto Nacional do Instituto Federal do Tocantins - IFTO. Centrada no seguinte questionamento: Quais os desafios enfrentados pelos professores bacharéis na área de computação ao abordar a temática ambiental durante suas aulas? E foi estabelecido como objetivo geral verificar quais os desafios enfrentados pelos professores bacharéis na área de computação ao abordar a temática ambiental durante suas aulas. Com o presente estudo, foi possível verificar que professores bacharéis têm como desafio abordar a temática ambiental durante sua prática em sala de aula nas respectivas disciplinas em que atuam, pois encontram dificuldades devido às bases tecnológicas serem especificamente na área da computação.

Palavras-chave: Educação Ambiental; Licenciatura em Computação; Transversalidade.

\footnotetext{
${ }^{1}$ Mestrando em Ciências Ambientais. Email: paulo.patricio@ifto.edu.br

2 Mestranda em Ciências Ambientais. E-mail: lilissanne@ifto.edu.br

${ }^{3}$ Mestranda em Ciências Ambientais. Email: artemarcia@ifto.edu.br

${ }^{4}$ Mestranda em Ciências Ambientais E-mail: cynthiasoliveira@outlook.com

${ }^{5}$ Mestrando em Ciências Ambientais. Email: sergio.machado@ifto.edu.br

${ }^{6}$ Mestrando em Ciências Ambientais. E-mail: lemoscec@hotmail.com
} 


\section{Introdução}

O tema meio ambiente tem se tornado assunto de grande discussão, principalmente no meio educacional, pois a natureza tem se mostrado insuficiente para dar conta dos desmazelos advindos do capitalismo, nessa necessidade incontrolável do ser humano em ter mais do que precisa.

A Educação Ambiental desde a década de mil novecentos e sessenta tem deixado de ser vista como algo relacionado à ecologia, pois perpassa as questões exclusivas da natureza. A problemática ambiental está relacionada às atividades sociais que impactam sobre a natureza.

Pensar a Educação Ambiental, no espaço escolar, é planejar práxis pedagógicas que levem a formação de sujeitos que pensem e pratiquem ações numa perspectiva de transformação da sua realidade.

Para tanto, a formação de sujeitos escolares em uma perspectiva crítica e transformadora requer investimento na elaboração e na efetivação de abordagens teóricometodológicas que propiciem a construção de concepções de mundo que se contraponham às concepções de que o sujeito é neutro; de que a educação consiste em acúmulo e transmissão de informações; de que o conhecimento é transmitido do professor ao aluno numa via de mão única; de que a ciência e seu ensino são banalizados por critérios positivistas, entre outras concepções fragmentadas de mundo (LOUREIRO; TORRES, 2014, p.15)

O Brasil, por meio da Lei 9795/99 sobre a Política Nacional da Educação Ambiental - PNEA, institui a obrigatoriedade da Educação Ambiental em todas as modalidades do ensino de forma transversal, no sentido de perpassar por todos os campos do conhecimento. Deste modo, ela não deve ser ofertada como disciplina específica, exceto nos cursos específicos de meio ambiente.

A transversalidade está relacionada às possibilidades de instituir no ambiente educativo a relação da teoria adquirida com a prática vivenciada. $A$ Educação Ambiental deve estar presente em todo o processo de ensino aprendizagem de forma contínua e permanente (BRASIL, 1999, p 30).

Esperar que somente as políticas públicas chamem atenção para reflexão e prática da Educação Ambiental é um equívoco. No entanto, elas estabelecem, orientam e fomentam projetos, programas, formação continuada de professores, material didático e outras estratégias, com maior ou menor sistematização e sucesso, para desenvolver a Educação Ambiental nas instituições de ensino, inclusive nos cursos de formação de professores nas universidades. Apesar de a Educação Ambiental ter se expandido, ela ainda é pouco abrangente e se caracteriza por ações pontuais e incipientes como prática a ser potencializada (TORALES, 2013).

Revbea, São Paulo, V. 12, № 2: 252-258, 2017. 
Freire (2002), ao discutir sobre o que diferencia o ser humano dos outros animais, discorre sobre a nossa capacidade de refletir, analisar, comparar, escolher, avaliar e optar. Esse pensamento leva a reflexão sobre a necessidade dos professores, em sua prática, problematizar situações do cotidiano real com seu aluno.

O curso de Licenciatura em Computação tem como objetivo formar educadores em computação, para atuar no mercado tecnológico e suprir as demandas referentes ao ensino de computação e utilização de tecnologias como ferramenta pedagógica, qualificando educadores e profissionais de outras áreas para a utilização dessas tecnologias.

Este estudo teve como objetivo verificar quais os desafios enfrentados pelos professores bacharéis na área de computação ao abordar a temática ambiental durante suas aulas.

Os autores utilizados para fundamentar este estudo foram Freire (2002); Lakatos e Marconi (2010); Gil (2010); Loureiro (2014); Imbernón (2006), Silva (2011) e Torales (2013).

\section{Metodologia}

Trata-se de uma pesquisa de campo, por ser utilizada com o objetivo de conseguir informações acerca de problemas, para qual se busca respostas ou descobrir novos fenômenos ou as relações entre eles. (LAKATOS; MARCONI, p.169, 2010). De acordo com os objetivos, tem caráter exploratório. Para (GIL, p. 27, 2010), as pesquisas exploratórias proporcionam uma maior familiaridade com o problema, com vistas a torná-lo mais explícito.

Utilizou-se, para análise dos dados, a pesquisa qualitativa, pelo motivo de que essa modalidade de pesquisa é a que melhor se aproxima da realidade a ser estudada, por envolver a obtenção de dados descritivos, colhidos no contato direto do pesquisador com a situação estudada enfatizando, assim, o processo e não o produto final.

Como técnica de coleta de dados, foram utilizados questionários e pesquisa no documento Projeto Pedagógico de Curso - PPC.

A pesquisa foi dividida em três etapas. A primeira etapa foi 0 levantamento das bibliografias para estudo e embasamento teórico, com a finalidade de subsidiar a análise dos dados coletados. A segunda etapa consistiu em aplicação de questionários aos professores com o objetivo de coletar os dados necessários para análise e discussão. A terceira etapa consistiu na análise dos dados coletados, sendo utilizada a abordagem qualitativa e a apresentação em gráficos. 


\section{Resultados}

O curso de Licenciatura em Computação do Campus Porto Nacional do Instituto Federal de Educação do Tocantins consta atualmente com 196 alunos matriculados. A estrutura curricular está distribuída em 8 (oito) períodos semestrais ao longo dos 4 (quatro) anos propostos para o curso, tempo mínimo para sua conclusão.

O curso conta com 12 professores bacharéis na área da computação, destes, 9 (nove) responderam ao questionário da pesquisa. Dos dados coletados, foram obtidos os resultados apresentados em formato de gráficos descritos a seguir.

O Gráfico 1 mostra que $56 \%$ dos professores pesquisados demonstram conhecimento sobre a transversalidade a ser utilizada na abordagem da temática ambiental, orientada pela Lei 9795/99. E ainda 44\% desses professores reconhecem que a temática ambiental deve ser abordada de maneira integrada, sistemática, continua e abrangente, tópico também disposto na referida lei. O gráfico demonstra que $100 \%$ dos professores pesquisados possuem o entendimento necessário sobre a abordagem da temática ambiental em sala de aula. No entanto, observa-se que na prática a abordagem sobre a temática ambiental se resume a eventos pontuais.

Gráfico 1: A Educação Ambiental de acordo com a Lei 9795/1999, deve estar inserida em todas as modalidades de ensino de forma transversal. Quanto à Educação Ambiental de forma transversal, podemos afirmar que:

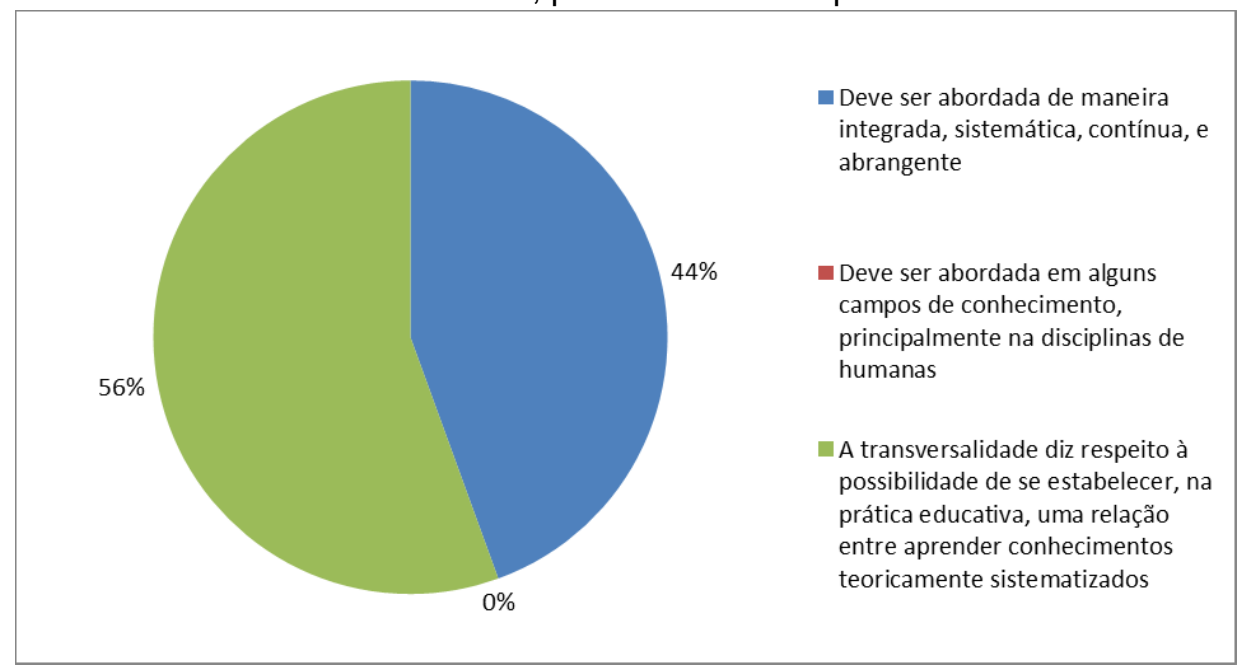

Fonte: elaborado pelos autores.

nua, e

Deve ser abordada em algun

campos de conhecimento

principalmente na disciplinas de

humanas

A transversalidade diz respeito à possibilidade de se estabelecer, na ntre aprender conhecimentos tericamente sistematizados

De acordo com os professores pesquisados, as ementas são técnicas e práticas da computação, e que não é possível abordar a temática, pois os conteúdos são específicos e não há como abrir espaços para reflexão sobre a Educação Ambiental. Somente 14\% dos professores afirmaram que refletem com os alunos sobre os problemas ambientais, mas não que conste no ementário do componente curricular (Gráfico 2). 
Gráfico 2: A Educação Ambiental consta ou deveria constar em todas as ementas das disciplinas do curso de licenciatura em Computação, principalmente por se tratar de curso de formação de professores. É possível verificar nessas ementas temas que abordam a problemática ambiental?

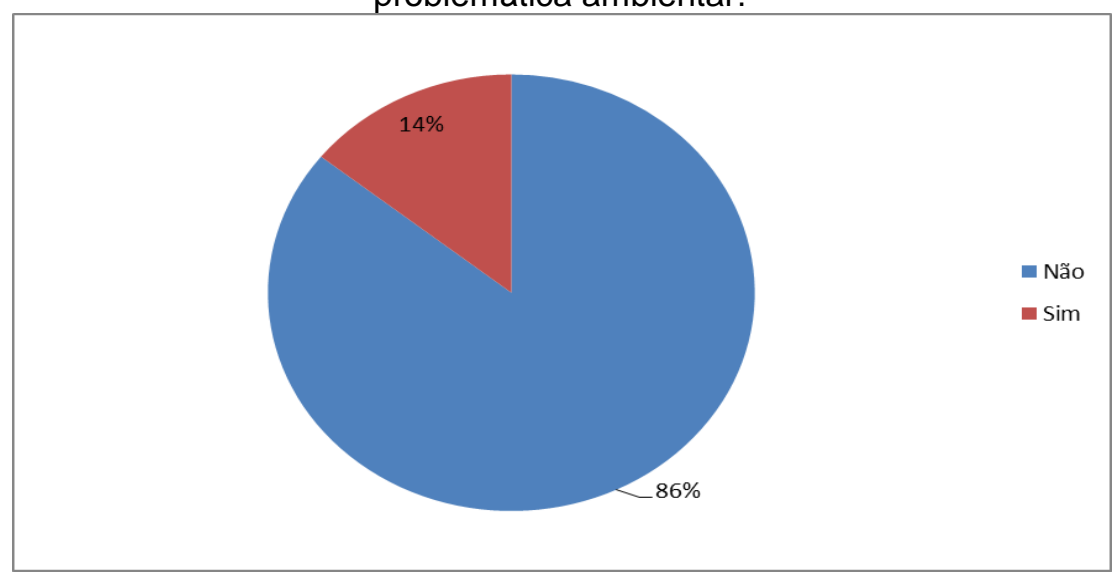

Fonte: elaborado pelos autores.

Os pesquisados têm como desafios abordar a temática ambiental no ensino, considerando as bases tecnológicas específicas da área da computação. Além disso, $11 \%$ apontam que falta formação contínua sobre a temática ambiental e sua abordagem no currículo (Gráfico 3).

Gráfico 3: Quais aos desafios encontrados ao abordar em sala de aula a temática sobre a problemática ambiental?

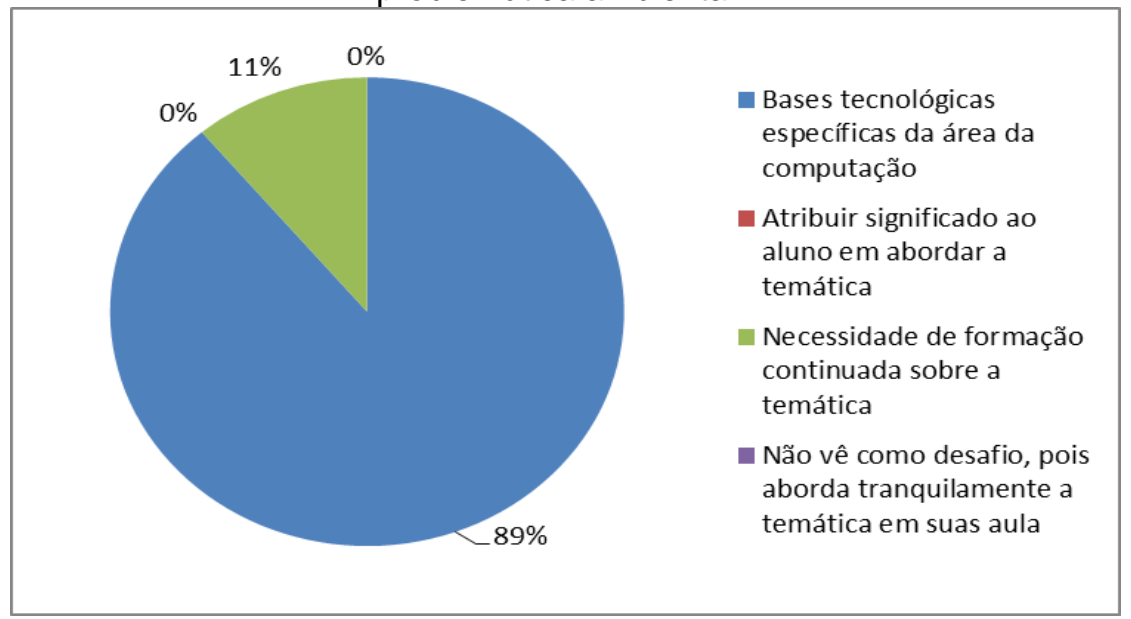

Fonte: elaborado pelos autores.

Encontram maior dificuldade em abordar a temática devido à ementa da disciplina ser específica da área de computação, o que não percebem espaços para reflexão sobre a temática ambiental. 


\section{Discussão}

O contexto atual requer profissionais conscientes quanto aos cuidados que se devem ter com o meio ambiente, pois a falta de ética ambiental e social têm impactado de forma intensa no contexto social.

$\mathrm{Na}$ discussão dos resultados dos dados coletados, o que se constata é que os professores compreenderam que a Educação Ambiental se faz necessária na formação de profissionais formadores de opinião e corroboram que as questões ambientais devem ser introduzidas no processo de ensino aprendizagem.

Entretanto, encontram dificuldades de inserir a temática em seu campo de atuação, ou seja, a computação. Isso nos faz refletir sobre a sua formação profissional, a qual está relacionada à aquisição de conhecimentos fundamentais, capacidades práticas, atitudes e formas de comportamentos que constituem base para o exercício de uma profissão e que nela não tenham sido abordadas as questões que se referem à Educação Ambiental.

A formação inicial é a etapa de preparação formal de futuros profissionais em uma instituição, a qual the proporcionará aquisição de conhecimentos disciplinares específicos para sua atuação. No entanto, a formação inicial é apenas uma etapa fundamental que possibilita orientações basilares sobre o trabalho a ser desenvolvido, exigindo do profissional, neste caso o docente, uma formação contínua, para poder acompanhar as profundas mudanças que vêm transformando aspectos culturais, ideológicas, sociais, profissionais e epistemológicas.

Com tudo isso, importa pensar a formação docente, pois as transformações repercutem na sua vida profissional e humana. Neste sentido a formação contínua é indispensável, pois possibilita a esses profissionais desenvolver práxis pedagógicas contextualizadas com as mudanças.

A formação de professores é um processo contínuo de desenvolvimento pessoal, profissional, político e social que não se constrói em alguns anos de curso, nem mesmo pelo acúmulo de cursos, técnicas e conhecimentos, mas pela reflexão coletiva do trabalho, de sua direção, seus meios e fins, antes e durante a carreira profissional (SILVA, 2011 p.15)

É importante salientar que a formação docente deve ser vista com o olhar do professor, partindo de suas necessidades e dos problemas que enfrentam na sala de aula. A realidade de cada escola é única, há questões específicas, que devem ser abordadas no processo contínuo da formação com o coletivo da escola, contribuindo para a formação coletiva dos profissionais inseridos na prática educativa.

Segundo Imbernón (2006, p.41), a formação permanente do docente inclui cinco eixos de atuação:

Revbea, São Paulo, V. 12, № 2: 252-258, 2017. 
1. A reflexão prático-teórica sobre a própria prática mediante a análise, a compreensão, a interpretação e a intervenção sobre a realidade. A capacidade do professor de gerar conhecimento pedagógico por meio da prática educativa.

2. A troca de experiências entre iguais para tornar possível a atualização em todos os campos de intervenção educativa e aumentar a comunicação entre os professores.

3. A união da formação a um projeto de trabalho.

4. A formação como estímulo crítico ante práticas profissionais como a hierarquia, o sexismo, a proletarização, o individualismo, o pouco prestígio etc., e práticas sociais como a exclusão, a intolerância etc.

5. O desenvolvimento profissional da instituição educativa mediante o trabalho conjunto para transformar essa prática. Possibilitar a passagem da experiência de inovação (isolada e individual) à inovação institucional.

Em se tratando da formação de bacharéis, que por consequência partem para atuação docente, percebem-se ausências de compreensão do processo de ensino aprendizagem como processo de mediação de informações em conhecimentos.

A introdução da Educação Ambiental na escola supõe pensar o currículo que atenda as exigências que a lei 9795/99 sobre a Política Nacional da Educação Ambiental - PNEA estabelece.

As Diretrizes Curriculares Nacionais, assim como a PNEA, mantêm a "compreensão integrada do meio ambiente em suas múltiplas e complexas relações para fomentar novas práticas sociais e de produção e consumo" (BRASIL, 2012, p. 4). Para isto, propõem novas relações disciplinares através de "prática educativa integrada e interdisciplinar" (BRASIL, 2012, p. 3), além da "abordagem curricular integrada e transversal, contínua e permanente em todas as áreas de conhecimento, componentes curriculares e atividades escolares e acadêmicas" (BRASIL, 2012, p.4).

\section{Conclusão}

Com o presente estudo, foi possível verificar que professores bacharéis em computação do curso de licenciatura em computação têm como desafio abordar a temática ambiental durante sua prática em sala de aula nas respectivas disciplinas em que atuam, pois encontram dificuldades devido às bases tecnológicas serem especificamente na área da computação.

Percebe-se que os professores bacharéis, apesar de compreenderem a importância desta abordagem para a formação dos futuros licenciados, carecem de formação continuada sobre a temática ambiental no currículo da computação. 
Outro aspecto percebido é a ausência da temática ambiental nas ementas das disciplinas das áreas específicas da computação, não atendendo a orientação de que a EA deve perpassar por todo o currículo de forma transversal, em se tratando da formação de professores.

\section{Referências}

BRASIL. Lei no 9.795, de 27 de abril de 1999. Dispõe sobre a Educação Ambiental, institui a Política Nacional de Educação Ambiental e dá outras providências.

BRASIL. Ministério da Educação. Conselho Nacional de Educação/Conselho Pleno. Resolução no 2, de 15 de junho de 2012. Diretrizes Curriculares Nacionais para a Educação Ambiental. Diário Oficial da União, Brasília, DF, 2012, 5p. Disponível em: <http://mobile.cnte.org.br:8080/legislacaoexterno/rest/lei/89/pdf>. Acesso em: 18/04/2017.

FREIRE, P. Pedagogia da autonomia: saberes necessários à prática educativa. 22.ed. são Paulo: Paz e terra, 2002.

IMBERNÓN, F. Formação docente profissional: formar-se para a mudança e a incerteza. 6 ed. São Paulo: Cortez, 2006. - (Coleção Questões da Nossa Época; v.77)

LOUREIRO, C.F.B.; TORRES, J.R. (Orgs.) Educação Ambiental: dialogando com Paulo Freire. 1 ed. São Paulo: Cortez, 2014.

SILVA, K. A formação de professores na perspectiva crítico-emancipadora. Linhas Críticas: revista da Faculdade de Educação. Universidade de Brasília: Brasília: FE/UNB, 2011.

TORALES, M.A. A inserção da Educação Ambiental nos currículos escolares e o papel dos professores: da ação escolar à ação educativo-comunitária como compromisso político-pedagógico. Revista Eletrônica do Mestrado em Educação Ambiental, Rio Grande/RS, v. especial, p. 1-17, mar. 2013. Disponível em: <http://www.seer.furg.br/remea/ article/viewFile/3437/2064>. Acesso em: 06/05/2017. 